\title{
Neutral Gases Adsorption With Hydrogen on Silicon Nanotubes: A Fuel Cell Invistegation
}

\author{
AZIN CHITSAZAN, M. MONAJJEMI* \\ H. AGHAEI* and M. SAYADIAN \\ Department of Chemistry, Science and research Branch, Islamic Azad University, Tehran, Iran. \\ ${ }^{*}$ Corresponding author E-mail: azinchitsazan @ gmail.com \\ http://dx.doi.org/10.13005/ojc/330337
}

(Received: February 17, 2017; Accepted: May 11, 2017)

\begin{abstract}
In the present study, adsorption of helium, neon, argon and binary mixtures of one of them with hydrogen on $(5,5)$ armchair silicon nanotube at Temperatures of 50,100 and $150 \mathrm{~K}$ and Pressures of $1,5,7,10$ and $15 \mathrm{MPa}$ were studied. For each binary mixture three different mole fractions of hydrogen were examined. Canonical Monte Carlo simulation by ab-initio calculation was employed for studding the adsorption of above gases on single-walled silicon nanotubes (SW-Si-NTS). The interaction energy of gases with the surfaces of the single Si-NTs obtained from quantum mechanics calculations was fitted to an exact potential functions used for simulating the system. Lennard-Jones potential was used for gas-gas and Morse potential was used for gas-silicon nanotubes interaction. The work was carried out at several temperatures and pressures by using Canonical-Monte-Carlo or CMC simulation in order for studding the effect of temperature and pressure on gas adsorption. The adsorption results showed that by increasing the pressure and decreasing the temperature, the amount of adsorption increases. It was concluded that among the rare gases discussed helium was lowest impact on hydrogen adsorption in a mixture of helium and hydrogen.
\end{abstract}

Keywords: Molecular simulation, Canonical Monte Carlo Simulation, Morse Potential Isotherm Adsorption, Fuel Cell

\section{INTRODUCTION}

Duo to environmental issues current researches are concentrated on new clean fuels, many studies have been focused on conversion of conventional fossil fuels to hydrogen because of lower pollutant emissions while hydrogen burning.
Considering potentials of the CarbonNano-Tubes or SW-CNTs and other non-materials for storage huge fuel gases and basically $\mathrm{H}_{2}{ }^{1,2}$, a numerous effort has been conducted, both experimentally ${ }^{3,4}$ and theoretically ${ }^{5,6}$ trying for exploring such a possibility ${ }^{3-7}$. 
Carbon nanotubes is an important lowdimensional nanomaterial because of its highly ${ }^{4}$ interesting properties ${ }^{5}$, such as narrow diameter ${ }^{6}$, high aspect ratio ${ }^{8}$, strong mechanical strength ${ }^{8,9}$, high chemical and thermal stabilities ${ }^{6-9}$, excellent heat conduction $^{9-12}$, interesting electronic and electrical properties and etc ${ }^{7-21}$.

Last decade, a few efforts have been focused on the hydrogen adsorption capacities of carbon nanotubes duo to their peculiar electronic and mechanical properties and potentials applications of the hydrogen for fuel ${ }^{12}$ cell vehicles $22-27$. However, many of those efforts has been failed for reaching the gravimetric ${ }^{22}$ densities proposed via the U.S. Department of Energies (6.5 Wt \%). Apparently, the designing of a novel material and a modified of porous material significantly increases the adsorption capacities of hydrogen ${ }^{28-30}$.

In a contrast of Carbon-based and Siliconbased nanomaterials ${ }^{27}$, in the terms of their PhysicoChemical properties ${ }^{25}$, is deeply ${ }^{26}$ rooted in attributes of the elements and its disparate atomic properties. Generally, Si differs from the $\mathrm{C}$ in five points as follows: (1)-lower electronegativity; (2)-kinetically more reactivity; (3) - larger atomic-radius ${ }^{26}$, and consequently larger orbitals; (4)-smaller energies differences between both $\mathrm{S}$ and the $\mathrm{P}$ orbitals, and consequently a lower hybridization ${ }^{26}$ energies; and (5)-the availabilities of energetically ${ }^{30}$ lowlying "d" orbitals and the abilities for expanding its coordination spheres ${ }^{31}$. Those properties of $\mathrm{Si}$ and their apparently contrast with $\mathrm{C}$, make Si chemistry and its material so interesting ${ }^{32}$ and worthy to study ${ }^{33}$.

One of the main factors that impact the chemicals and physicals properties of $\mathrm{Si}$ in comparison with those of carbons are the larger atomic sizes of $\mathrm{Si}$ that has longer $\mathrm{Si}-\mathrm{Si}=2.35 \AA$ bonds $^{34}$ in size and weaker bonds with the bond energies of $222, \mathrm{Kj} / \mathrm{mol}$, comparing to carbon-carbon bonds equal $1.54 \AA$ including bond energy $=345.6 \mathrm{Kj} / \mathrm{mol}^{33}$.

Further more, the poor $\pi-\pi$ overlapping for $\mathrm{Si}, \mathrm{Si}-\mathrm{Si}=2.16 \AA$ with bond energies equal $327 \mathrm{Kj} / \mathrm{mol}$ are much weaker than the carbon-carbon bonds (1.34Å) with bond energies equal $602 \mathrm{Kj} / \mathrm{mol}^{34}$.
This disparity leads to a existence ${ }^{35}$ of varieties in the organic chemistry and nonmaterial like graphite carbon, fullerenes and carbon Nano tubes, whereas ${ }^{36}$ exist only a few number of stable molecules including $\mathrm{Si}=\mathrm{Si} \pi$ bonding $^{2}$. In the cases of Nano-tubes contrasting with the CNTs, the analogous Si-NTs based on rolled up graphene like sheet seems to be relatively not easily synthesized ${ }^{34}$, but its existence on a basis of various experimental or theoretical investigation has been reported.

Eberl and Schmidt first have demonstrated the possibilities of the rolling up for a thin Si films ${ }^{30-32}$ . Moreover to this, Yang has been reported a novel synthesis of the large diameters around e" $50 \mathrm{~nm}$ Si-NTs using the chemical vapour deposition methods while using the transmission-electronmicroscopy or TEM techniques ${ }^{33}$ in 2002. After that, $\mathrm{Lee}^{35}$ published a paper related on the growth of pure silicon Nano -tubes using molecular beam epitaxia ${ }^{35}$ on the porous alumina without any catalysts ${ }^{34}$. Tang published two works which has been reported the growth of silicon Nano-tubes including a smaller diameter around $13 \mathrm{~nm}$ using silicon oxide via hydrothermal synthesis ${ }^{35,36}$.

To our knowledge, the most interesting results on the synthesis and characterization ${ }^{35}$ of a thin and presumably single-walled silicon Nano-tubes provided by De Crescenzi, through experimental studies $^{37,38}$

The successful synthesises of silicon nanotubes caused to a wide investigations for assessing the suitability of silicon Nano-tubes bundles $^{37}$ as a candidate material for adsorbing efficiently $\mathrm{H}_{2}$. On the aforementioned comparison, between carbon and silicon, silicon has lot electrons in the outer shells, which leads to a higher polarizabilities and stronger dispersion ${ }^{36}$ forces. Correspondingly, the silicon Nanotubes may show a large and stronger van-der-Waals attraction ${ }^{36}$ for hydrogen rather than Carbon Nano-tubes. Therefore, it has been reported a multiscale theoretical method for investigating adsorption of instance gases in the silicon Nano-tubes arrays ${ }^{36}$.

The rest of those papers are organized as follows ${ }^{36-38}$. (1)-the binding energies between adsorbent and adsorbate obtained from ab-initio 
calculations were fitted for a propering potential function ${ }^{36}$. So the result was applied as an input ${ }^{36}$ in the canonical Monte-Carlo simulation for evaluateing capacities of adsorption of instance gases on SiNT at different pressures, temperatures and mole fractions of mixture. The amount of $\mathrm{H}_{2}$ adsorption in pure and mixture forms on SiNt were also compared to each other.

\section{Methods and Calculations}

Computational methods are well placed to a multiscale theoretical approach that combines the first-principle calculation for obtaining the binding energies between instance gases and the SiNt and Canonical-Monte-Carlo (CMC) simulation ${ }^{39}$ for obtaining the weight percentage of pure rare gases and $\mathrm{H} 2$ in a mixture of each one of rare gases that might be stored in pure SiNt arrays at different thermodynamic conditions.

The first principles quantum chemical calculations applied for investigating of the nature in the gases interactions with the single $(5,5)$ SiNt were accomplished in a DFT system using the package Gaussian $03^{40}$. Duo to its relatively small diameter, the cylinder cluster model of $\mathrm{Si}_{70} \mathrm{H}_{20}$ was selected for SiNT $(5,5)$ that appears nanotube properties in the lowest possible of length. In the first step, the geometries of the model were optimized.

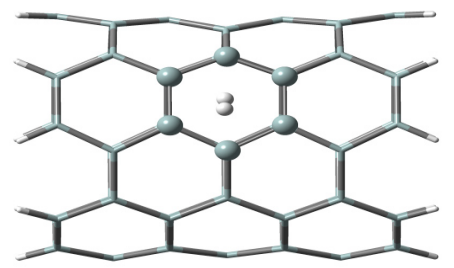

Fig. 1: The energetically favourable orientations for hydrogen e adsorption on the $(5,5)$ Si-NTs.

Table1: The parameters of Morse-potential used for describing the interactions between the fluid molecules and Si-NTs

\begin{tabular}{lcccc}
\hline & $\begin{array}{c}\mathbf{H}_{2}-\mathbf{S i} \\
\text { NT }\end{array}$ & $\begin{array}{c}\mathrm{He}-\mathrm{Si} \\
\text { NT }\end{array}$ & $\begin{array}{c}\mathbf{N e}-\mathbf{S i} \\
\text { NT }\end{array}$ & $\begin{array}{c}\text { Ar-Si } \\
\text { NT }\end{array}$ \\
\hline $\mathrm{D}($ Kcal $/ \mathrm{mol})$ & 0.777 & 0.3373 & 0.8 & 0.9288 \\
$\mathrm{~g}$ & 5.277 & 6.126 & 5.944 & 6.85 \\
$\mathrm{r}_{\mathrm{e}}(\AA)$ & 3.2053 & 3.778 & 3.313 & 3.805 \\
\hline
\end{tabular}

In all of the calculations, the gases molecules and their nearest six $\mathrm{Si}$ atoms have been treated with a $6-311++G^{\star *}$ basis set, whereas the next atoms were treated with commonly used 4-21G basis set, carried out by the MP1PW91 $1^{41}$ exchangecorrelation function, which can be provided a more exact dispersion forces rather than B3LYP ${ }^{42,43}$. On nanotube surface, there are several adsorption sites, depending on the position and orientation of gas molecules: the molecule can be located in the above of $\mathrm{Si}$ atoms, the bridge of $\mathrm{Si}$-Si bonds and the centre of silicon hexagon or hollow ${ }^{44}$. All those cases have been occurred into account for adsorption of all gases in the Si-NTs surfaces. The results have shown among different adsorption position, the hollow $^{44}$ sites with the $\mathrm{H}-\mathrm{H}$ bond vertical on the tube surfaces are the most favourable adsorption mode for the outside SiNT wall (see figure 1). This phenomenon has already been observed for adsorption of hydrogen on $\mathrm{CNT}^{30}$ and $\mathrm{SiNT}^{45}$ surface. The orientation (horizontal or vertical) of gas molecules only considered for hydrogen molecule because the noble gas molecules were described as spherically symmetric.

An efficient way to implement the results obtains from first-principle calculation in the CMC simulation $^{45}$, which is an accurate-potential-function to bridge both kinds of calculation.

In this work, the ab-initio potential energies results of the gases with SiNt were fitted for a number of usual system 'functions', and it has been found that the Morse- potential ${ }^{46}$ in eq. 1 is the best selection. The parameters in the Morse-potential ${ }^{46}$ have been obtained according to the fitted binding energies for the molecules in the surfaces which are as close as possible of determining by the firstprinciple calculations described formerly. It is worth mentioning that the Morse-potential has been used successfully to fit interaction potential computed by the $1^{\text {th }}$ principle calculations in the previous works ${ }^{46-49}$.

The interactions between the fluid molecules and the surfaces of the nanotubes were fitted to the Morse- potential, and the form is expressed as follows:

$U_{i}=2 D\left[x^{2}-2 x\right] \quad, \quad x=\exp \left(-\gamma / 2\left(r_{i} / r_{2}-1\right)\right)$ 
Where $r_{i}$ is the distance between fluid molecule and the tubes surfaces $(\AA)$. The values of the constant $D, \gamma$ and $r_{e}$ for gas adsorption outside the nanotube are given in the Table 1.

As previously mention, we used a CMC-simulation to study the adsorptions of the gases on the $(5,5)$ SWSiNT. The intermolecular interaction was modelled by the typical 12 - 6 Lennard-Jones pair potential:

$\Phi_{\text {LJ }}(r)=4 \varepsilon_{\mathrm{ff}}\left[\left(\sigma / \mathrm{r}_{\mathrm{i}}\right)^{12}-\left(\sigma / \mathrm{r}_{\mathrm{i}}\right)^{6}\right]$

Where, $\left\{\boldsymbol{\varepsilon}_{\mathrm{ff}}\right.$ and $5_{\mathrm{fff}}$ are the energies and the length parameter in the Lenard Jones potentials, and $\{r\}$ denoted the centre-towards-centre distances. The subscriptions of $\{\mathrm{ff}\}$ stand for interaction between two section fluid molecules and $\left\{\varphi /{ }_{\llcorner\mathrm{J}}\right\}$ represent the full Lenard Jones potentials.

Cross parameters of the unlike pair $\mathrm{i}$ and $\mathrm{j}$

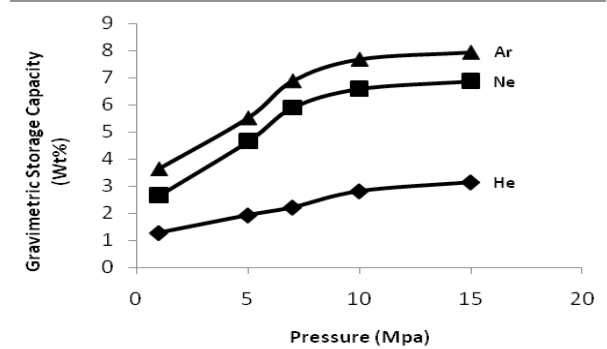

(a) particles were obtained using the Lorentz-Berthelot mixing rules:

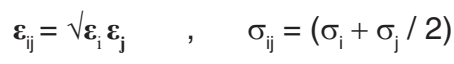

All the interaction potential parameters are given in Table $2^{50-51}$. Details of the method can be found elsewhere ${ }^{52,53}$.

The Monte-Carlo simulation is based on the probabilistic phenomenon and concepts. In these methods a system composed of $\mathrm{N}$ interacting atoms which are given a set of initial coordinates and orientations. The evolutions of these initial configurations are then generated by successive random displacements of the atoms. The ensemble averages, $\langle f\rangle$, of the physical quantities $\mathrm{f}\left\langle\gamma^{N}\right\rangle$, of function of $\mathrm{N}$ particles coordinates, such as the potential energies, are then obtained as an unweighted average over the resulting set of configurations ${ }^{54}$. Typically between $10^{6}-10^{5}$ configurations are

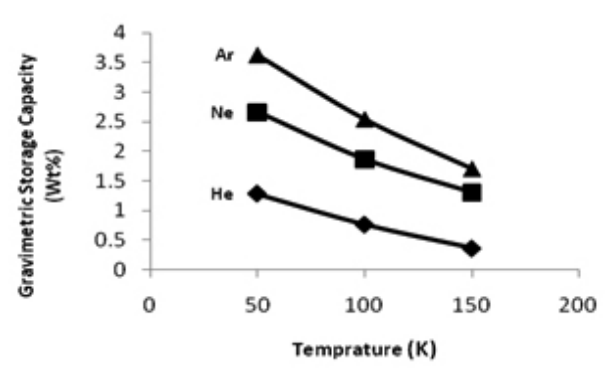

(b)

Fig. 1: Asorption isotherms of $\mathrm{He}, \mathrm{Ne}$ and $\mathrm{Ar}$ as function of pressure and temprature, (a) adsorption istherms of $\mathrm{He}, \mathrm{Ne}$ and $\mathrm{Ar}$ in variuos pressure at $50 \mathrm{~K}$, (b) adsorption isotherms of $\mathrm{He}, \mathrm{Ne}$ and $\mathrm{Ar}$ in variuos temprature at $1 \mathrm{Mpa}$.

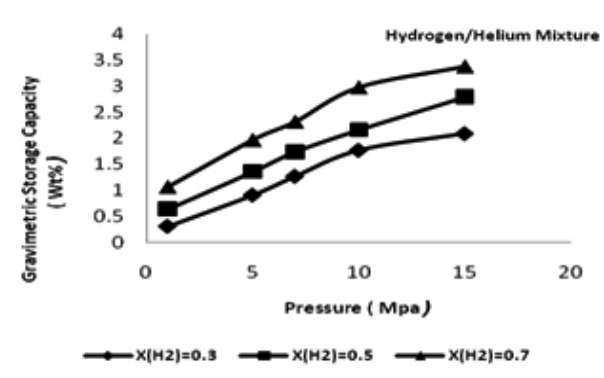

(a)

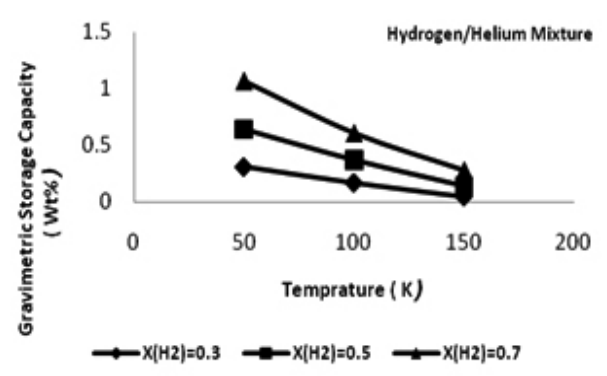

(b)

Fig. 2: adsorption isotherms of Hydrogen/Helium mixture in three mole fractions $\left(x_{H}=0.3,0.5\right.$ and 0.7$),(a)$ adsorption isotherms as function of pressure at $50 \mathrm{~K}$, (b) adsorption isotherms as function of temperature at $1 \mathrm{Mpa}$ 
generated. In the Monte Carlo approach, no time scales are involved, and the orders in which configurations occur have no particular significance. In most practical applications, the objectives have been estimated Canonical ensemble ${ }^{54}$ averages, representing the systems composed of fixed number of particles ${ }^{54}, \mathrm{~N}$, confined to a fixed volume, $\mathrm{V}$ and at a fixed pre-set temperature, $\mathrm{T}^{54}$.

In this work, an armchair type SW-Si-NTs $(5,5)$ with highly symmetrical structures, with 200 atoms and diameter of $37 \AA$ was selected in our systems. The simulation box used are around 100.00 $\AA \times 100.00 \AA \times 45.00 \AA$ ) contained one SW-SiNTs. The cut off radius was 2.5 times the collision diameter. The number of the gases molecules in the simulation box (a box with 100.0 $\AA$ × $100.00 \AA$ $\times 45.00 \AA$ dimensions) can be easily calculated at the special temperatures and pressures using virial equation of state ${ }^{54}$.

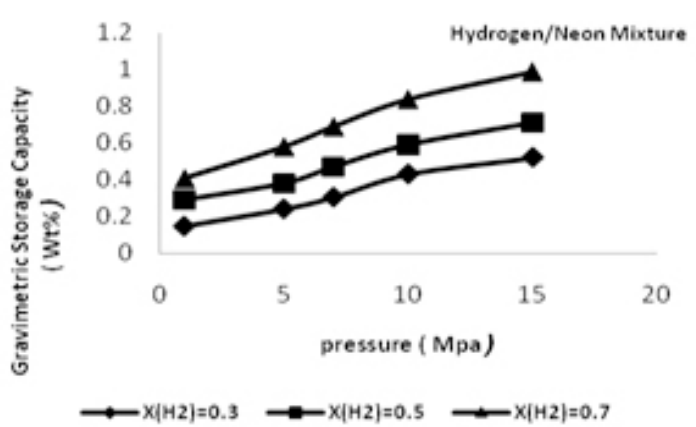

(a)
Periodic boundaries conditions were applied in all three dimensions ${ }^{54}$. For each state point, C-M-C simulation consisted of $5 \times 10^{7}$ configurations that $2 \times 10^{7}$ steps were to guarantee equilibration and $3 \times 10^{7}$ steps were to sample the desired thermodynamic properties ${ }^{54}$.

Furthermore, for obtaining adsorption isotherms, the common parameters were calculated as follows. Gravimetric storage capacities, $\rho_{w}$, were calculated as follows too:

$\rho_{\mathrm{w}}=\frac{N_{\text {gas }}{ }^{\prime} m_{\text {gas }}}{N_{\text {gas }}{ }^{\prime} m_{\text {gas }}+N_{S i}{ }^{\prime} m_{S i}}$

Where $\mathrm{N}_{\mathrm{Si}}$ and $\mathrm{N}_{\text {gas }}$ are the number of $\mathrm{Si}$ atoms and gas molecules in our simulation box, and $\mathrm{m}_{\mathrm{gas}}$ and $\mathrm{m}_{\mathrm{Si}}$ are the related molar masses, respectively.

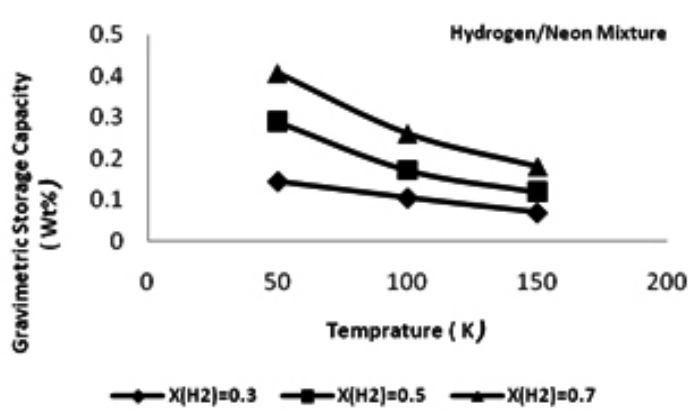

(b)

Fig. 3: adsorption isotherms of Hydrogen/Neon mixture in three mole fractions $\left(x_{H}=0.3,0.5\right.$ and 0.7$),(a)$ adsorption isotherms as function of pressure at $50 \mathrm{~K}$, (b) adsorption isotherms as function of temperature at $1 \mathrm{Mpa}$.

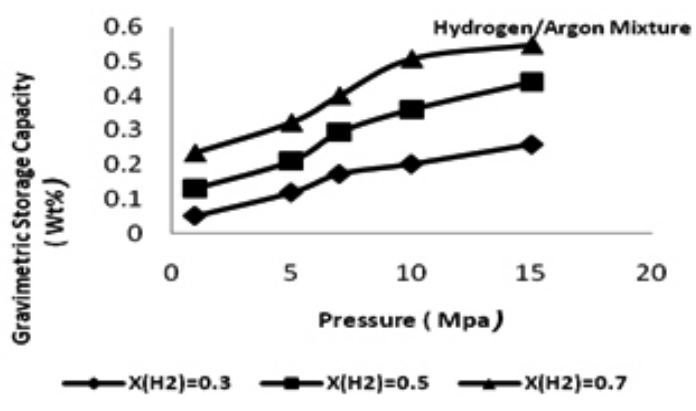

(a)

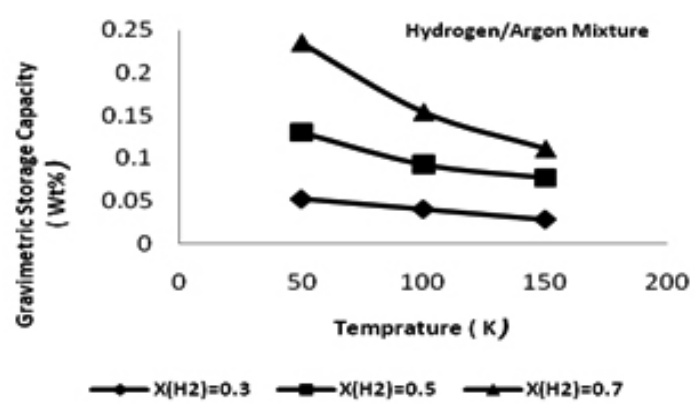

(b)

Fig. 4: adsorption isotherms of Hydrogen/Argon mixture in three mole fractions $\left(x_{H}=0.3,0.5\right.$ and 0.7$),(a)$ adsorption isotherms as function of pressure at $50 \mathrm{~K}$,

(b) adsorption isotherms as function of temperature at $1 \mathrm{Mpa}$. 


\section{RESULTS AND DISCUSSIONS}

Adsorption of pure $\mathrm{He}, \mathrm{Ne}$ and $\mathrm{Ar}$ on $(5,5)$ SiNT. The adsorption behaviours of rare gases on $(5,5) \mathrm{SiNT}$, according to eq. (3), are evaluated at one subcritical (50K) and two supercritical (100 and $150 \mathrm{~K})$ and pressure ranging between 1 to $15 \mathrm{Mpa}$. The simulation results are exhabited in fig. 1.

All the adsorption isotherms for $\mathrm{He}, \mathrm{Ne}$ and Ar were characterized by type I (Langmuir shape). The intrinsic properties of type I isotherms are that adsorptions are limited to a completion of the single monolayer of adsorbate at the adsorbent surfaces. Type I isotherms (parabolic behaviour) are visible for the adsorption of gases on microporous ${ }^{55-57}$ solids whose sizes (pore) are not much larger than the molecular diameters of the adsorbate which complete filling of those narrow pores ${ }^{55}$. Moreover, adsorption isotherms imply that condensation is prohibited ${ }^{55}$. Capillary condensation observes when the pores have diameters larger than approximately 2 $\mathrm{nm}$ at adequately ${ }^{55}$ low temperature. It is notable that with a diameter less than $2 \mathrm{~nm}$, no condensations

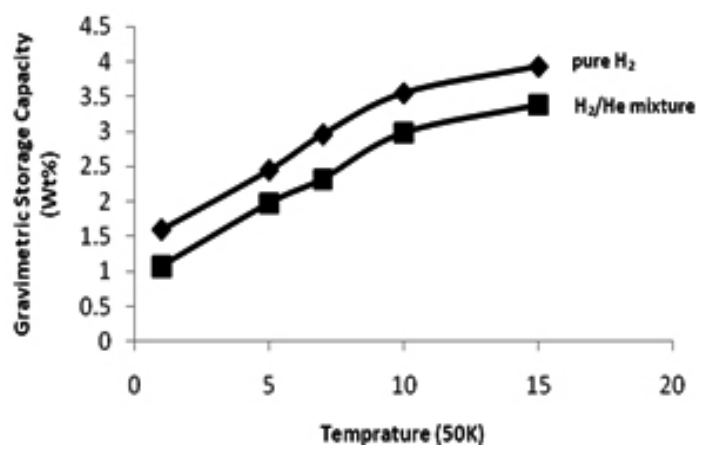

Fig. 5: Comparison of stored hydrogen between $\mathrm{x}_{\mathrm{H}}=0.7$ and $\mathrm{x}_{\mathrm{He}}=0.3$ mixture and pure hydrogen conditions on $(5,5) \mathrm{SiNT}$ in various pressure at $50 \mathrm{~K}$.

Table 2: Lennard-Jones potential parameters

\begin{tabular}{lcc}
\hline Interaction & $\varepsilon / k_{\bar{E}}$ & $\mathbf{5 ( \AA )}$ \\
\hline $\mathrm{H}_{2}-\mathrm{H}_{2}$ & 37 & 2.928 \\
$\mathrm{He}-\mathrm{He}$ & 10.2 & 2.56 \\
$\mathrm{Ne}-\mathrm{Ne}$ & 35.6 & 2.75 \\
$\mathrm{Ar}-\mathrm{Ar}$ & 120 & 3.4 \\
\hline
\end{tabular}

are occurred because the system becomes onedimensional ${ }^{56}$, as for SW-CN-Ts. Those explanations are proved with the experimental result for Neon adsorption ${ }^{57}$ and molecular simulation results for Helium, Xenon and Argon mixture ${ }^{59}$.

The adsorption isotherms of Helium, Neon and Argon are plotted in figures $1 \mathrm{a}$ and $1 \mathrm{~b}$ as function of pressure at $50 \mathrm{~K}$ (figure1a) and temperature at $1 \mathrm{Mpa}$ (figure 1b). Three $\mathrm{He}, \mathrm{Ne}$ and $\mathrm{Ar}$ adsorption isotherms exhibit similar behaviours. Comparing the amount of $\mathrm{He}, \mathrm{Ne}$ and $\mathrm{Ar}$ adsorbed, it can be seen in figure 1 that the amount of Ar adsorbed is more than that of $\mathrm{Ne}$ and the amount of $\mathrm{Ne}$ adsorbed is more than that of $\mathrm{He}$ at the pressure and temperature range specified ${ }^{55}$. These are duo to the fact that the gases molecules can varies considerably in the sizes, physical properties, structures and electric properties (dipole and quadruple moments). Hence, Ar has stronger interaction and greater adsorption capacity on SiNTs than $\mathrm{Ne}$ that is more than $\mathrm{He}$, under identical conditions.

\section{Adsorption of $\mathrm{H}_{2}$ in mixture with rare gases on $(5,5)$ SiNT}

It is well known that hydrogens are the most promising alternative fuels because of their cleanness and high energies density ${ }^{60,61}$. Although it is a gas with critical temperature $\{33.19 \mathrm{~K}\}^{62}$, above this temperature hydrogen cannot be liquefied and is unsafe for storage and transported ${ }^{62-84}$. In this work, we consider hydrogen in binary mixture with each rare gas ( $\mathrm{He}, \mathrm{Ne}$ and $\mathrm{Ar}$ ) as a solution for safer storage of hydrogen as well as overall the substitution of hydrogen for other flues as fuel cell vehicles.

As we all know, the temperature, pressure and bulk composition play an important role in the adsorption process. For all considered binary mixtures, the gravimetric storage capacities of hydrogens in three mole fraction $\left(x_{H}=0.3,0.5\right.$ and 0.7 ) are illustrated in figure 2,3 and 4 . To investigate the adsorption behaviour at different pressure and temperature, temperature and pressure were set at $50 \mathrm{~K}$ (figure $2 \mathrm{a}, 3 \mathrm{a}$ and $4 \mathrm{a}$ ) and $1 \mathrm{Mpa}$ (figure $2 \mathrm{~b}$, $3 \mathrm{~b}$ and $4 \mathrm{~b}$ ) respectively. As we can observe, the variation patterns of $\mathrm{H}_{2}$ adsorption with pressure and temperature is similar to pure $\mathrm{He}, \mathrm{Ne}$ and $\mathrm{Ar}$ adsorption. It is obvious, these calculation indicates that the amount of storage capacity of hydrogen in $\mathrm{x}_{\mathrm{H}}=0.7$ is higher than other mole fractions. The 
corresponding adsorption isotherms are shown in figure 2-4. In addition, it can be shown in the figure $2 a$ that the greatest gravimetric adsorption amount of hydrogen is in $\mathrm{x}_{\mathrm{H}}=0.7$ and $\mathrm{x}_{\mathrm{He}}=0.3$ mixture, duo to the interaction manner of fluid molecules together and fluid molecules with Si-NTs.

Comparison of $\mathrm{H}_{2} / \mathrm{He}$ mixture and pure $\mathrm{H}_{2}$ adsorptions on $(5,5)$ SiNT

Fig. 5 depicts a gravimetric storages capacities for pure hydrogen and $1 / 3$ hydrogen/ helium mixtures on the $(5,5) \mathrm{Si}-\mathrm{N}$-Ts as a function of pressure at $50 \mathrm{~K}$. As it can be seen from this figure, both isotherms of adsorption are characterized by Langmuir shape, and there is no observation of capillary condensation. Obviously, amount of pure hydrogen adsorption is larger than hydrogen/helium mixture adsorption due to difference between fluid - fluid interaction in mixture and pure condition. In other words, in mixture level of simulation hydrogen molecules not only interact with other hydrogen molecules but have interaction with helium molecule and the number of hydrogen molecules captured by helium molecules. Consequently, hydrogen molecules have lower interaction with SiNT in the mixture level.

In this part, despite the lower amount of stored hydrogen in $\mathrm{x}_{\mathrm{H}}=0.7$ and $\mathrm{x}_{\mathrm{He}}=0.3$ mixture, this system is safer than that of pure hydrogen as a system for storage hydrogen in its applications as fuel cell vehicles.

\section{CONCLUSIONS}

For investigating the effect of pressure, temperature and bulk composition in the adsorption behavior of hydrogens, helium, argon and neon, 5 pressures in the range from $1-15 \mathrm{Mpa}$, three temperatures $(50,100$ and $150 \mathrm{~K})$ and three mole fraction $(0.3,0.5$ and 0.7$)$ in mixture condition were considered. In all studies, the adsorption capacity for adsorption of pure helium, argon, and neon, mixture of each instance rare gases with hydrogen at different mole fractions and pure hydrogen are increasing functions of pressure and decreasing functions of temperatures.

As an amazing result from this research, in $\mathrm{x}_{\mathrm{H}}=0.7$ and $\mathrm{x}_{\mathrm{He}}=0.3$ mixture, despite comparatively larger amount of stored hydrogen in pure hydrogen condition on $(5,5)$ Si-NTs, this system is safer, i.e. duo to use rare gases, dangerous of explosion in bulk storage of hydrogen decrease in its application as fuel cell vehicles and amount of gravimetric storage capacity in this condition is approximately close the pure hydrogen adsorption.

\section{REFERENCES}

1. lijima $S$.,Nature, 1991, 354:56

2. Lithoxoos GP, Samios J, Carissan YJ, J, Phys Chem C, 2008, 112:16725

3. Dillon AC, Jones KM, Bekkedahl TA, Kiang $\mathrm{CH}$, Bethune DS, Heben M J Nature, 1991, 386: 377-379

4. Dillon AC, Bekkedahl TA, Jones KM, Heben M J Fullerenes, 1999, 3:716-727

5. Darkrim F, Levesque D J Chem Phys, 1998, 109:4981-4984

6. Wang Q, Johnson JK J Phys Chem, B, 1999 103:4809-4813

7. Wildoer JWG, Venema LC, Rinzler AG, Smalley RE, Dekker C Nature, 1998, 391:59

8. Odom TW, Huang JL, Kim P, Lieber CM Nature, 1998, 391:62
9. Charlier JC, Lambin P Phys Rev B,1998 57:R15037

10. Zhou G, Duan WH, Gu BL Chem Phys Lett 2001,333:344

11. Hamada N, Sawada S, Oshiyama A Phys Rev Lett , 1992,68:1579

12. Saito R, Dresselhaus G, Dresselhaus MS Physical Properties of Carbon Nanotubes. Imperial College Press, London, 1998

13. Ouyang $\mathrm{M}$, Huang $\mathrm{JL}$, Cheung $\mathrm{CL}$, Lieber $\mathrm{CM}$ Science, 2001 292:702

14. Collins PC, Arnold MS, Avouris P Science, 2001 292:706

15. lijima S, Brabec C, Maiti A, Bernholc J J Chem Phys 1996, 104:2089

16. Thess A, Lee R, Nikolaev P, Dai HJ, Petit P, Robert J, Xu CH, Lee YH, Kim SG, Rinzler 
AG, Colbert DT, Scuseria GE, Tomanek D, Fischer JE, Smalley RE Science, 1996, 273:483

17. Journet C, Maser WK, Bernier P, Loiseau A, DelaChapelle ML, Lefrant S, Deniard P, Lee R, FischerJE Nature, 1997, 388:756

18. Mintmire JW, Dunlap BI, White CT Phys Rev Lett 1992,68:631

19. Saito R, Fujita M, Dresselhaus G, Dresselhaus MS Appl Phys Lett, 1992, 60:2204

20. Saito R, Dresselhaus MG, Dresselhaus MS Phys Rev B, 2000, 61:2981

21. Saito R, Fujita M, Dresselhaus $G$, Dresselhaus MS Phys Rev B, 1992, 46:1804

22. Liu C, Fan YY, Liu M, Cong HT, Cheng HM, Dressethaus MS Science, 1999, 286:1127

23. Zhang XR, Cao DP, Chen JF J Phys Chem B 2003, 107:4942

24. Wang Q, Johnson JK J Phys Chem B, 1999, 103:4809

25. Yin YF, Mays T, McEnaney B Langmuir, 2000 16:10521

26. Eric M, Pierre B Langmuir, 2004, 20:7852

27. Cao DP, Wang WC Int $J$ Hydrogen Energy, 2007 32: 1939

28. Zhao YF, Kim YH, Dillon AC, Heben MJ, Zhang SB Phys Rev Lett, 2005, 95:155504

29. Cao DP, Feng PY, Wu JZ Nano Lett, 2004 4:1489

30. Mpourmpakis G, Froudakis GE, Lithoxoos GP, Samios J Nano Lett, 2006,6:1581

31. Teo BK, Sun XH Chem Re, 2007, 107:14541532

32. Schmidt OG, Eberl K Nature, 2001. 410:168

33. Sha J, Niu J, Ma X, Xu J, Zhang X, Yang Q, Yang D Adv Mate, 2002, 14:1219-1221

34. Jeong SY,Kim JY, Yang HD, Yoon BN, Choi SH, Kang HK, Yang CW, Lee YH Adv Mater,2003, 15:1172-1176

35. Chen YW, Tang YH, Pei LZ, Guo C Adv Mater 2005, 17:564-567

36. Tang YH, Pei LZ, Chen YW, Guo C Phys Rev Lett , 2005,95:116102-116104

37. De Crescenzi M, Castrucci P, Scarcelli M, Diociauti M, Chaudhari PS, Balasubramanian C, Bhave TM, Bhoraskar SV Appl Phys Lett, 2005, 86:231901-231903

38. Castrucci P, Scarcelli M, De Crecsenzi M, Diociauti M, Chaudhari PS, Balasubramanian
C, Bhave TM, Bhoraskar SV Thin Solid Films, $2006,508: 226-230$

39. Frankel D, Smit B Understanding Molecular Simulation: From Algorithms to Applications. $2^{\text {nd }}$ ed., Academic press, San Diego, 2002

40. Frisch MJ, Trucks GW, Schlegel HB, Scuseria GE, Robb MA, Cheeseman JR, Montgomery $\mathrm{JA}, \mathrm{Jr}$, Vreven T et al Gaussian 03, revision B.0; Gaussian, Inc. Wallingford, CT, 2004

41. Perdew PJ, Wang Y Phys Rev B, 1992 , 45:13244

42. Lee C, Yang W, Parr RG Phys Rev B, 1988, 37:785

43. Becke AD J Chem Phys, 1993, 98:5648

44. Mpourmpakis G, Tylianakis E, Froudakis GE J. Nanosci. Nanotechnol. 2006 , 6:87

45. Ryou J, Hong S, Kim G Solid State Communications 2008, 148:469-471

46. Han SS, Goddard WA J Am Chem Soc, 2007 129:8422

47. Smith R, Nock C, Kenny SD, Belbruno JJ, Vece MD, Palomba S, Palmer RE Phys Rev B, 2006, 73:125429

48. Jiang $A Q$, Awasthi N, Kolmogorov AN, Setyawan W, Borjesson A, Bolton K, Harutyunyan AR, Curtarolo S Phys Rev B, 2007, 75:205426

49. Vervisch W, Mottet C, Goniakowski J Phys Rev B 2002, 65:245411

50. Steele WA Surf Sci, 1973, 36:10651

51. Morales JJ, Nuevo MJ J Comput Chem,1995, 16:105

52. Allen MP, Tildesley DJ Computer simulation of liquids. Clarendon Press, Oxford, 1987

53. Frenkel D, Smit B Understanding Molecular Simulation: From Algorithms to Applications. Elsevier, New York, 2002

54. Rafii-Tabar H Physics Reports, 2004, 390:235 $-452$

55. Thomas WJ, Crittenden B Adsorption Technology and Design. Elsevier, 1998

56. Cao D, Wu JZ Langmuir, 2004, 20:3759

57. Krungleviciute V, Heroux L, Talapatra S, Migone AD Nano Lett, 2004, 4:1133

58. Firlej L, Kuchta B Colloids and Surfaces A. Physicochem Eng Aspects, 2004, 241: 149-154

59. Greathouse JA, Kinnibrugh TL, Allendorf MD Ind Eng Chem Res, 2009, 48:3425

60. Ritter JA, Ebner AD, Wang J, Zidan R 
Implementing a hydrogen Economy. Mater Today, 2003, 6:18-23

61. Elam CC, Padro CEG, Sandrock G, Luzzi A, Lindblad P, Hagen EF Realizing the hydrogen future: the international energy agency's efforts to advance hydrogen energy technologies. Int J Hydrogen Energy ,2003 28:601-7

62. Li Y, Zhao D, Wang Y, Xue R, Shen Z, Li X (Int $\mathrm{J}$ Hydrogen Energy, 2006, 32:2513-2517

63. Monajjemi, M. Biophysical Chemistry. 2015 207,114-127

64. Bagheri,S.; Moosavi,M.S.; Moradiyeh,N.; Zakeri,M.; Attarikhasraghi,N.; Saghayimarouf,N.; Niyatzadeh,G.; Shekarkhand,M.; Mohammad S. Khalilimofrad, Ahmadin,H.; Ahadi,M.; Molecules 2015, 20, 21636-21657.

65. Monajjemi, M. Theor Chem Acc, 2015, 134:77

66. Monajjemi, M. Journal of Molecular Modeling , 2014, 20, 2507

67. Lee, V.S.; Khaleghian, M.; B. Honarparvar, B.; F. Mollaamin, F. J. Phys.Chem C. 2010, 114, 15315

68. Monajjemi, M. Struct Chem. 2012, 23,551580

69. Monajjemi, M.; Boggs, J.E. J. Phys. Chem. A, 2013, 117, 1670 "1684

70. Rahimi, A.; Orient. J. Chem. 2016, 32, 6, 2957-296559.

71. Monajjemi, M.; Khaleghian, M, Journal of
Cluster Science. 2011, 22 (4)), 673-692 318

72. Monajjemi, M. Chemical Physics. 2013, 425, 29-45

73. Monajjemi, M.; Wayne Jr, Robert. Boggs, J.E. Chemical Physics. 2014, 433, 1-11

74. L Mahdavian, F Mollaamin, B Honarparvar, Fullerenes, Nanotubes and Carbon Nanostructures,2010, 18 (1), 45-55, 2010

75. Raoufi, F.; Aghaee, H.; Orient. J. Chem. 2016,32, 4, 1839-1858

76. Elsagh, A., Zare, K., Orient. J. Chem. 2016, 32, 5, 2585-2598

77. Monajjemi, M. Falahati, M.; Mollaamin, F.; Ionics, 2013, 19, 155-164

78. Monajjemi, M., Chahkandi, B. Journal of Molecular Structure: THEOCHEM, 2005, 714 (1), 28, 43-60.

79. Tahan, A.; Mollaamin, F.; Russian Journal of Physical Chemistry A, 2009, 83 (4), 587597

80. Soofi, N.S., Orient. J. Chem. 2016, 32, 11, 2327-2345

81. M.; Ketabi, S.; Amiri, A. Russian Journal of Physical Chemistry, 2006, 80 (1), S55-S62

82. Monajjemi, M.; Baheri, H.; Mollaamin, F. Journal of Structural Chemistry.2011, 52(1), 54-59

83. Heshmat, M.; Haeri, HH, Biochemistry (Moscow), 2006, 71 (1), S113-S122

84. Khaleghian, M.; Mollaamin, F. Molecular Simulation. 2010, 36, 11, 865-870. 